\title{
Previsão da Perda de Rendimento de Grãos de Soja Causada pela InfestaÇão de Plantas daninhas Utilizando Variáveis FOLIARES RELATIVAS ${ }^{1}$
}

\author{
Prediction of Soybean Grain Yield Loss Due to Weeds Infestation Using Relative Leaf Variables
}

\author{
RIZZARDI, M.A. ${ }^{2}$, FLECK, N.G. ${ }^{3}$, AGOSTINETTO, D. ${ }^{4}$ e BALBINOT JR., A.A. ${ }^{4}$
}

\begin{abstract}
RESUMO - O desenvolvimento de modelos que visam prever os danos causados pela infestação de plantas daninhas no rendimento de grãos das culturas agrícolas inclui a identificação de variáveis explicativas e de modelos matemáticos apropriados para estimar esses danos. O objetivo deste trabalho foi ajustar modelos matemáticos com a inclusão de uso de variáveis foliares relativas, integrando parâmetros alternativos, na quantificação das perdas de rendimento de grãos de soja causadas pela infestação das plantas daninhas por picão-preto (Bidens spp.) e guanxuma (Sida rhombifolia). Foram realizados experimentos em campo, utilizando-se épocas de semeadura da soja após a dessecação da cobertura vegetal e densidades de picão-preto ou guanxuma como fatores, além de bioensaios com soja em monocultura e em associação com picão-preto ou guanxuma. Em campo, avaliaram-se as áreas e coberturas foliares das plantas daninhas e da cultura 20 dias após a emergência (DAE) da soja. Nos bioensaios, avaliou-se a massa seca da soja aos 60 DAE. A inclusão de um segundo parâmetro (m) no modelo da hipérbole retangular, que limita a perda máxima de rendimento, melhora os ajustes do modelo quando se utilizam área ou cobertura foliar relativas como variáveis explicativas. Parâmetros obtidos em bioensaios podem ser integrados com dados de campo, o que auxilia a predição das perdas de rendimento de grãos de soja causadas pela infestação de plantas daninhas.
\end{abstract}

Palavras-chave: área foliar relativa, cobertura do solo, Bidens spp., Sida rhombifolia, interferência.

ABSTRACT - The development of models that can provide early estimates of crop grain yield losses caused by weed infestation involves identifying explicative variables and mathematical models suited to characterize such losses. The aim of this research was to adjust mathematical models including relative leaf variables, by integrating alternative parameters to quantify losses in soybean grain yield due to the interference of beggarticks (Bidens spp.) and arrowleaf sida (Sida rhombifolia) infestation. Field experiments were carried out using soybean seeding times after plant cover desiccation and beggarticks and arrowleaf densities as main factors as well as bioassays using soybean in monoculture and in association with beggarticks or arrowleaf. Field trials evaluated crop and weed relative leaf area and soil coverage 20 days after soybean emergence (DAE). The bioassays evaluated soybean dry matter 60 DAE. Inclusion of a second parameter $(m)$ in the rectangular hyperbolic model, which limits yield maximum loss, improves model fitting when relative leaf area or soil coverage are used as explicative variables. Bioassay parameter estimates can be integrated with field data, improving prediction of soybean grain yield losses due to weed infestations.

Key words: $\quad$ relative leaf area, soil coverage, Bidens spp., Sida rhombifolia, interference.

\section{INTRODUÇÃO}

Os programas para manejo de plantas daninhas requerem estimativas quantitativas dos seus efeitos no rendimento de grãos das culturas. Os níveis de dano para implementar ações visando decidir se é necessário ou não controlar as plantas daninhas podem ser

Recebido para publicação em 15.5.2002 e na forma revisada em 2.4.2003.

2 Eng.-Agr., Dr., Prof. da Faculdade de Agronomia e Medicina Veterinária da UPF, Caixa Postal 611, 99001-970 Passo Fundo-RS, <rizzardi@upf.tche.br>. ${ }^{3}$ Eng.-Agr., Ph.D., Prof. da Faculdade de Agronomia da UFRGS, <fleck@ufrgs.br>, Bolsista do CNPq. ${ }^{4}$ Eng.-Agr., M.S., Aluno do Programa de Pós-Graduação em Fitotecnia da UFRGS. 
estimados por equações de regressão que quantificam as perdas de rendimento como uma função do nível de infestação de plantas daninhas algum tempo após a emergência da cultura (Kropff et al., 1992).

Geralmente, os modelos utilizados consideram a perda de rendimento como uma função da densidade de plantas daninhas e/ou da época de sua emergência em relação à cultura (Cousens, 1985; Cousens et al., 1987; Oliver, 1988; Sartorato et al., 1996). No entanto, os resultados derivados desses modelos realçam certas limitações associadas ao uso exclusivo da densidade de plantas daninhas como base para a previsão de perdas no rendimento, pois a avaliação daquela variável não leva em conta a época relativa de emergência e tampouco as variações no tamanho das plantas daninhas (Storkey et al., 1997), além de outros fatores do ambiente.

Na tentativa de superar as limitações dos modelos baseados na densidade e na época relativa de emergência, Kropff \& Spitters (1991) introduziram um modelo empírico que relaciona as perdas de rendimento com a área foliar das plantas daninhas em relação à da cultura, estimada em uma época específica após a emergência da cultura. O ponto inicial na derivação do modelo representa a resposta do rendimento da cultura à densidade de plantas, a qual geralmente é descrita por uma hipérbole retangular (Kropff \& Spitters, 1991). Esses autores também sugeriram que a área foliar relativa pode refletir tanto diferenças de densidade quanto de época relativa de emergência das plantas daninhas (Chikoye \& Swanton, 1995; Knezevic et al., 1995). Desse modo, o modelo poderia ser usado em situações nas quais as plantas daninhas emergissem em fluxos separados, mas determinando-se a área foliar relativa das plantas daninhas apenas uma vez, isto é, na época de decisão para aplicação do controle (Lotz et al., 1994).

No modelo de área foliar relativa proposto por Kropff \& Spitters (1991), a equação hiperbólica relaciona a perda de rendimento da cultura à área foliar das plantas daninhas em relação à da própria cultura, usando um coeficiente de dano ("q") designado como único parâmetro do modelo. Por esse modelo, o parâmetro "q" integraria os efeitos dos parâmetros "i” (perda de rendimento por unidade de planta daninha quando sua densidade se aproxima de zero) e "a" (perda de rendimento quando a densidade de plantas daninhas tende ao infinito) do modelo proposto originalmente por Cousens (1985). Além disso, o coeficiente de dano relativo (q) representa um índice da competitividade das plantas daninhas sobre a cultura, isto é, quanto maior for seu valor, mais competitiva é a planta daninha sobre a cultura e, desse modo, estima-se uma maior perda de rendimento da cultura provocada pela planta daninha (Chikoye \& Swanton, 1995; Knezevic et al., 1995).

Posteriormente, o modelo de área foliar relativa foi estendido para um modelo que engloba dois parâmetros, o qual também computa a variável que representa a perda máxima do rendimento da cultura ("m") (Lotz et al., 1996). A inclusão deste parâmetro adicional, que limita a perda máxima de rendimento em $100 \%$, fornece uma clara assíntota para a curva hiperbólica (Chikoye \& Swanton, 1995). Diversos autores verificaram que esse modelo de dois parâmetros, o qual computa a perda máxima de rendimento, conduz a um melhor ajustamento aos dados, quando comparado ao modelo de um só parâmetro, com base na comparação dos quadrados médios do resíduo (Chikoye \& Swanton, 1995; Knezevic et al., 1995; Lotz et al., 1996). Embora o valor do parâmetro " $m$ " possa variar entre locais e anos, dependendo do ambiente, sua inclusão pode ajudar a explicar a variabilidade freqüentemente observada nas estimativas de perda de rendimento entre diferentes condições (Chikoye \& Swanton, 1995). Para experimentos com uma única espécie daninha presente, a qual origine baixa perda de rendimento, o modelo que geralmente melhor se ajusta aos dados inclui o parâmetro "m" (Van Acker et al., 1997).

Estudos também demonstraram que, em estádios iniciais de crescimento, a cobertura foliar, definida como a proporção do solo (porcentagem) ocupada pela projeção vertical do dossel de uma espécie, pode ser usada para determinar valores das variáveis de entrada em modelos de predição (Lotz et al., 1994). Quando o dossel ainda não estiver completamente fechado, a área foliar relativa correlaciona-se fortemente com a cobertura foliar, a qual é uma variável relativamente fácil de avaliar (Kropff \& Spitters, 1991). As regressões lineares 
entre cobertura foliar relativa e área foliar relativa, calculadas através de três métodos por Vitta \& Fernandez Quintanilla (1996), foram sempre significativas, e o coeficiente de determinação $\left(R^{2}\right)$ variou entre 0,70 e 0,95. De forma semelhante, Berti \& Sattin (1996) observaram que, quando a densidade foi considerada como variável independente, a espécie Xanthium strumarium, de alto potencial competitivo, mostrou pequena variação entre os anos do estudo; por outro lado, para Echinochloa crusgalli, o fator anos influenciou marcadamente as estimativas. Já quando foi usada a cobertura foliar relativa as diferenças entre as duas espécies desapareceram e a variabilidade entre anos foi reduzida.

Este trabalho objetivou ajustar modelos matemáticos baseados em variáveis foliares relativas, integrando parâmetros alternativos na quantificação das perdas de rendimento de grãos de soja causadas por picão-preto (Bidens spp.) e guanxuma (Sida rhombifolia).

\section{MATERIAL E MÉTODOS}

Experimentos em campo e bioensaios em casa de vegetação foram conduzidos durante o período 1998-2000. Os experimentos em campo foram conduzidos na Faculdade de Agronomia e Medicina Veterinária da Universidade de Passo Fundo (UPF), em Passo Fundo, região fisiográfica do Planalto Médio do Rio Grande do Sul, e na Estação Experimental Agronômica da Universidade Federal do Rio Grande do Sul (EEA/ UFRGS), em Eldorado do Sul-RS, região fisiográfica da Depressão Central. Dois dos experimentos foram conduzidos durante a estação de crescimento 1998/99 em Passo Fundo (ambiente 1), e dois o foram em 1999/00, em Eldorado do Sul (ambiente 2). Os bioensaios foram instalados em 2000/01 na Faculdade de Agronomia da UFRGS (FA/UFRGS), em Porto Alegre-RS.

Os solos das áreas experimentais são classificados como Latossolo Vermelho distrófico típico e Argissolo Vermelho distrófico típico, para Passo Fundo e Eldorado do Sul, respectivamente (Embrapa, 1999).

\section{Experimentos conduzidos em campo}

O delineamento experimental utilizado nos experimentos foi completamente casualizado, em esquema fatorial, sem repetição. Nos dois ambientes, os tratamentos representativos do fator A constaram de densidades de picão-preto (Bidens pilosa e B. sulbalternans, em infestações mistas) ou de guanxuma (Sida rhombifolia), e os do fator B, de épocas de semeadura da soja em relação à data de dessecação da cobertura vegetal existente nas áreas. No ambiente 1, a semeadura da soja foi realizada aos $3,7 \mathrm{e}$ 11 dias após a dessecação (DAD), tanto no experimento com picão-preto quanto no de guanxuma. No ambiente 2 , a semeadura da soja foi realizada aos 3 , 7 e 11 DAD no experimento com picão-preto, e aos 20, 24 e 28 DAD naquele com guanxuma.

As densidades de plantas daninhas foram alocadas aleatoriamente no campo, de acordo com níveis populacionais encontrados naturalmente nas áreas. No ambiente 1, para picãopreto utilizaram-se 17 unidades em cada época de semeadura da soja, cujas densidades variaram de 1 a 180 plantas $\mathrm{m}^{-2}$, totalizando 51 unidades com infestação; para guanxuma foram utilizadas 15 unidades em cada época, com densidades que variaram de 1 a 60 plantas $\mathrm{m}^{2}$, perfazendo um total de 45 unidades com infestação. No ambiente 2, para picão-preto utilizaram-se 10 unidades em cada época de semeadura, cujas densidades variaram de 1 a 110 plantas $\mathrm{m}^{-2}$, totalizando 30 unidades com infestação; para guanxuma, utilizou-se 10 unidades em cada época, com densidades que variaram de 1 a 128 plantas $\mathrm{m}^{2}$, perfazendo um total de 30 unidades com infestação. Em todos os experimentos mantiveram-se quatro ou cinco unidades com ausência de plantas daninhas, em cada uma das épocas de semeadura da soja. Cada unidade experimental mediu $6 \mathrm{~m}^{2}(2 \mathrm{~m} \times 3 \mathrm{~m})$, constando de cinco fileiras de soja espaçadas em 0,4 m.

Os experimentos foram implantados utilizando-se o sistema de semeadura direta em áreas contendo cobertura vegetal composta por aveia-preta (Avena strigosa) e algumas espécies daninhas. O manejo da cobertura vegetal foi realizado com os herbicidas glyphosate (900 g e.a. hà) e 2,4-D (670 g e.a. ha ${ }^{-1}$ ), efetuado por ocasião do florescimento das plantas de aveia-preta. Nos experimentos conduzidos no ambiente 1 e naquele estabelecido com picão-preto no ambiente 2 , procedeu-se a uma segunda dessecação com o herbicida paraquat (300 $\mathrm{g} \mathrm{ha}^{-1}$ ), três dias antes da primeira época

Planta Daninha, Viçosa-MG, v.21, n.1, p.45-54, 2003 
de semeadura da soja, em cada um dos experimentos, para eliminar as plantas daninhas que não foram controladas com a primeira dessecação e, também, plantas daninhas que emergiram no período entre a primeira e a segunda dessecação. Para guanxuma, no ambiente 2, foi realizada somente uma dessecação, 20 dias antes da primeira época de semeadura da soja.

Para o ambiente 1, a adubação do solo foi efetuada por ocasião da semeadura da soja, através da distribuição de $300 \mathrm{~kg} \mathrm{ha}^{-1}$ da fórmula 5-20-30. No ambiente 2 , a adubação foi realizada através da distribuição de $340 \mathrm{~kg}$ hà da fórmula 5-25-25. Em ambos os experimentos utilizou-se o cultivar de soja Embrapa 66, de ciclo médio de desenvolvimento e estatura média de $83 \mathrm{~cm}$, o qual foi estabelecido na densidade de 400 mil plantas ha ${ }^{-1}$, em espaçamento de $0,4 \mathrm{~m}$ entre as fileiras. No ambiente 1, a semeadura da soja foi realizada em 27 de novembro, 1 e 5 de dezembro no experimento com guanxuma, e em 1,5 e 9 de dezembro para o experimento com picão-preto. No ambiente 2 , a semeadura da cultura deuse em 17, 21 e 25 de novembro, no experimento com guanxuma, e em 8, 12 e 16 de dezembro, para o experimento com picão-preto.

O controle de plantas daninhas gramíneas nos experimentos foi obtido com o herbicida graminicida clethodim ( $120 \mathrm{~g} \mathrm{ha}^{-1}$ ), acrescido do adjuvante Assist a 0,5\% v/v. Durante a condução dos experimentos foram realizadas suplementações hídricas por meio de irrigações por aspersão, a fim de se garantir adequado desenvolvimento à cultura.

As determinações de área foliar das plantas daninhas foram realizadas a partir de plantas coletadas em duas áreas de $0,5 \mathrm{~m}^{2}$, numa extremidade de cada unidade experimental, aos 20 dias após a emergência da soja (DAE). A área foliar da soja foi determinada em cinco plantas colhidas, por parcela, com auxílio de integrador eletrônico de área foliar.

A cobertura foliar do solo por plantas daninhas e cultura foi avaliada de forma visual, aos 20 DAE. A avaliação foi realizada utilizando-se escala percentual, em que a nota 0 correspondeu à ausência de cobertura do solo e a nota 100 significou cobertura completa do solo. No ambiente 1, a avaliação foi realizada por dois avaliadores que atuaram de modo independente, os quais atribuíram individualmente suas notas, que foram somadas para obtenção das respectivas médias. No ambiente 2 , essa estimativa foi realizada por um só avaliador.

A contribuição relativa da área foliar das plantas daninhas foi calculada de acordo com a equação 1, proposta por Vitta \& Fernandez Quintanilla (1996). Procedimento similar foi adotado no cálculo da cobertura foliar relativa:

$$
\mathrm{A}_{\mathrm{fr}}=\left(\mathrm{A}_{\mathrm{fe}}\right) /\left(\mathrm{A}_{\mathrm{fe}}+\mathrm{A}_{\mathrm{fc}}\right) \quad \text { (equação 1) }
$$

em que $\mathrm{A}_{\mathrm{fr}}=$ área foliar relativa; $\mathrm{A}_{\mathrm{fe}}=$ área foliar da planta daninha $\mathrm{m}^{-2}$; e $\mathrm{A}_{\mathrm{fc}}=$ área foliar da cultura $\mathrm{m}^{-2}$.

O rendimento de grãos de soja foi determinado em área de $3,0 \mathrm{~m}^{2}(1,2 \times 2,5 \mathrm{~m})$, englobando as três fileiras centrais das parcelas. Por ocasião da pesagem dos grãos foi determinada sua umidade e, posteriormente, os pesos obtidos foram uniformizados para $13 \%$ de umidade. Aos dados de rendimento foram calculadas as perdas percentuais em relação às parcelas mantidas livres de plantas daninhas, conforme descrito por Rizzardi (2002).

Aos dados de percentagem de perda foram ajustados modelos de regressão não-linear, com base na hipérbole retangular, propostos por Kropff \& Spitters (1991) e por Lotz et al. (1996):

$\mathrm{P}_{\mathrm{r}}=\left(100^{*} \mathrm{q}^{*} \mathrm{X}\right) /\left(1+\left((\mathrm{q}-1)^{*} \mathrm{X}\right)\right) \quad$ (equação 2)

$\mathrm{P}_{\mathrm{r}}=(100 * \mathrm{q} * \mathrm{X}) /(1+((\mathrm{q} / \mathrm{m})-1) * \mathrm{X}) \quad($ equação 3)

em que: $\mathrm{P}_{\mathrm{r}}=$ perda de rendimento (\%); $\mathrm{X}=$ área foliar ou cobertura foliar relativa; $q=$ coeficiente de dano relativo, estimado pelo modelo; e $\mathrm{m}=$ perda máxima de rendimento, estimada pelo modelo.

Os ajustes dos modelos aos dados foram realizados usando-se o procedimento Proc Nlin do programa computacional SAS (SAS, 1989). Neste procedimento, utilizou-se o método de Gauss-Newton, o qual, por sucessivas iterações, estima os valores dos parâmetros nos quais a soma dos quadrados dos desvios das observações em relação aos valores ajustados é mínima.

Os modelos da hipérbole foram ajustados individualmente para as variáveis explicativas 
em cada ambiente e, dentro de cada ambiente, para cada época de semeadura da soja, independentemente da identificação de presença de interação entre ambientes e épocas. Esse procedimento foi adotado para permitir a comparação dos modelos testados, a qual se deu em função dos coeficientes de determinação $\left(\mathrm{R}^{2}\right)$ e das somas de quadrados do resíduo (SQR). A escolha do melhor modelo ajustado baseou-se na combinação do maior valor de $\mathrm{R}^{2}$ e do menor valor de SQR.

Após a escolha do melhor modelo preditivo, fez-se a comparação dos modelos ajustados entre ambientes, procedendo-se, inicialmente, à análise de homogeneidade da variância pelo teste de Bartlett (Gomez \& Gomez, 1984). Nos casos em que houve homocedasticidade, foi realizada comparação entre os ambientes e entre as épocas de semeadura da soja, utilizando-se método proposto por Chow (Florez et al., 1999).

\section{Bioensaios em casa de vegetação}

Os bioensaios foram instalados em vasos com capacidade volumétrica para $8 \mathrm{~L}$ e altura de $25 \mathrm{~cm}$. Um deles avaliou a soja em monocultura e os outros dois compararam associações de picão-preto ou guanxuma com soja, cujas plantas conviveram durante a fase vegetativa da soja. O delineamento experimental utilizado nos bioensaios foi o completamente casualizado, com quatro repetições.

Inicialmente, foi instalado um bioensaio com soja em monocultura, em densidades de duas, quatro, seis e oito plantas por vaso, semeadas eqüidistantes e à profundidade uniforme. Na seqüência, foram conduzidos bioensaios de substituição, mantidos em densidade constante de oito plantas por vaso, utilizandose cinco proporções de plantas de picão-preto e soja ou de guanxuma e soja $(0: 8 ; 2: 6 ; 4: 4$; $6: 2 ; 8: 0)$. Nos três bioensaios utilizou-se o cultivar de soja Embrapa 66, que foi semeado três dias antes da semeadura das plantas daninhas. Esse procedimento permitiu que plantas daninhas e cultura emergissem simultaneamente, uma vez que as sementes das plantas daninhas foram pré-germinadas em laboratório para garantir que tivessem emergência uniforme nos vasos.
As plantas de soja e plantas daninhas foram colhidas aos 60 DAE, coincidindo com o florescimento da soja. Nessa ocasião, foram feitas avaliações de área foliar e massa seca da parte aérea da soja. A área foliar foi avaliada conforme método descrito anteriormente nos experimentos conduzidos em campo. Para obtenção da massa seca da soja, fez-se o corte da parte aérea das plantas ao nível do solo e a secagem do material colhido foi efetuada em estufa com circulação forçada de ar, à temperatura de $60{ }^{\circ} \mathrm{C}$, até o material atingir peso constante.

Aos dados de massa seca da soja foi aplicada análise de regressão linear através do recíproco da produção de massa por planta como variável dependente e do recíproco da densidade de plantas como variável independente, conforme metodologia descrita por Roush et al. (1989). Os parâmetros "q" e "m" foram obtidos com base na análise proposta por Kropff \& Spitters (1991):

$$
\begin{array}{ll}
\mathrm{q}=\left(\mathrm{b}_{\mathrm{ce}} / \mathrm{b}_{\mathrm{c}}\right) *\left(\mathrm{AF}_{\mathrm{c}} / \mathrm{AF}_{\mathrm{ce}}\right) & \text { (equação } 4) \\
\mathrm{e} & \text { (equação } 5)
\end{array}
$$

em que: $b_{c e}$ e $b_{c}=$ coeficientes "b" das equações lineares recíprocas dos bioensaios de substituição (cultura e planta daninha) e soja em monocultura, respectivamente; $\mathrm{AF}_{\mathrm{c}}=$ área foliar da soja na ausência da planta daninha; e $\mathrm{AF}_{\mathrm{ce}}=$ área foliar da soja na presença da planta daninha.

Os valores de "q" e " $\mathrm{m}$ " foram incorporados na equação 3 , obtendo-se então modelos matemáticos específicos para picão-preto e guanxuma. Com esses modelos, foram estimadas as perdas de rendimento derivadas dos valores de cobertura foliar relativa observados em campo por Rizzardi (2002), com o método fotográfico. Com dados de cobertura foliar observados e estimados, procedeu-se à análise de correlação linear simples.

\section{RESULTADOS E DISCUSSÃO}

Os modelos ajustados através da área foliar relativa como variável independente apresentaram baixa capacidade preditiva, tanto para picão-preto quanto para guanxuma, principalmente nas semeaduras realizadas aos 7 e

Planta Daninha, Viçosa-MG, v.21, n.1, p.45-54, 2003 
11 DAD (Tabela 1). Para essas épocas de semeadura, no caso do picão, os ajustes obtidos foram inferiores aos conseguidos com o uso da variável densidade da planta daninha (Rizzardi, 2002). Esses resultados denotam que o modelo que estima perdas de rendimento com base na área foliar relativa apresenta restrições para essas plantas daninhas, que podem estar associadas à precisão e/ou à época de avaliação. Nesse contexto, os modelos baseados na área foliar relativa geralmente apresentam validade apenas quando utilizados em estádios iniciais do ciclo de crescimento (Vitta \& Fernandez Quintanilla, 1996) e para espécies em que a altura dominante entre espécies da associação cultura-plantas daninhas não se altere durante a estação de crescimento (Hashem et al., 1998). O ajuste não-satisfatório dos modelos baseados na área foliar relativa nos experimentos com picão-preto, nos ambientes 1 e 2, e com guanxuma, no ambiente 2 , pode estar associado ao maior crescimento em estatura das plantas daninhas em relação à cultura a partir do florescimento da soja, o que caracterizou mudanças na altura relativa do dossel da associação cultura-plantas daninhas. Contudo, apenas esse fato não explica o baixo ajuste observado para guanxuma no ambiente 1 .

Para área foliar relativa, o uso do modelo com dois parâmetros (equação 3) ajustou-se melhor aos dados do que o modelo de um parâmetro (Equação 2) (Tabela 1), o que se comprova tanto pelos maiores valores de $\mathrm{R}^{2}$ quanto pelos menores valores de SQR. Os melhores ajustes resultaram da inclusão de um limite de perda máxima de rendimento ("m"). Isso fez com que houvesse diminuição na tendência de aumento linear para perdas de rendimento quando se usou a equação 2 , a qual considera somente o parâmetro "q". Como a inclusão do parâmetro " $\mathrm{m}$ " define claramente uma assíntota, comumente ele é necessário para conjuntos de dados contendo baixas perdas máximas de rendimento. Já em experimentos em que a perda máxima de rendimento devido à interferência da espécie daninha for alta, superando mesmo $100 \%$, a inclusão do parâmetro "m" no modelo não se justificaria (Van Acker et al., 1997).

Outro aspecto que chama atenção na Tabela 1 é o fato de que a adição do parâmetro "m" ao modelo resultou em valores bem maiores de "q", comparando-se aos valores obtidos com o modelo de um parâmetro, o que dificulta a interpretação do significado desse parâmetro. Ou seja, se o parâmetro "q" já representava a perda de rendimento tanto em baixos quanto em altos valores de área foliar relativa, a inclusão do parâmetro "m" no modelo torna difícil definir quantitativamente "q". Para Kropff \& Spitters (1991), o parâmetro "q" representa um índice que indica a intensidade de interferência da planta daninha em relação à cultura, em que altos valores de "q" indicam maior competitividade da planta daninha e, portanto, maiores perdas potenciais de rendimento.

Apesar de os ajustes observados serem qualitativamente baixos, percebe-se que a utilização da variável área foliar relativa incorporou os efeitos das épocas de semeadura (Tabela 2). A ausência de efeito de épocas, quando do uso do modelo de dois parâmetros, ressalta uma vantagem do uso do modelo baseado na área foliar relativa, ou seja, os índices de área foliar das plantas daninhas e da cultura necessitam ser avaliados apenas num ponto no tempo, enquanto a época relativa de emergência requer observações praticamente diárias (Kropff et al., 1992; Norris, 1992; Chikoye \& Swanton, 1995). Além disso, resultados obtidos com simulação de dados demonstraram existir estreita relação entre área foliar relativa das plantas daninhas e perda de rendimento sobre ampla faixa de densidades de plantas daninhas e de épocas relativas de sua emergência (Kropff \& Lotz, 1992).

Além dos aspectos negativos já relacionados quanto ao uso de modelos que se baseiam em área foliar relativa, estes podem apresentar outros problemas adicionais. Por exemplo, a habilidade em avaliar precisa e rapidamente as áreas foliares da cultura e das plantas daninhas limita grandemente a aplicação prática desses modelos. As áreas foliares relativas não são fáceis nem práticas de serem medidas e sua determinação é demorada (Weaver, 1991; Vitta \& Fernandez Quintanilla, 1996). Além do mais, a medição dos índices de área foliar da cultura e das plantas daninhas é um procedimento que envolve amostragem trabalhosa e destrutiva. Esta abordagem poderia ser muito proveitosa caso estivessem disponíveis métodos acessíveis para detectar prontamente a área 
foliar das plantas daninhas, conforme ocorre com a cobertura foliar relativa (Lotz et al., 1994).

Os resultados da análise de correlação linear simples indicaram associação entre área foliar relativa e cobertura foliar relativa para picão-preto $(\mathrm{r}=0,46 ; \mathrm{p}<0,05)$, porém, para guanxuma, essa associação foi baixa $(r=0,20$; $\mathrm{p}=0,17$ ). De outra parte, a análise das relações de perda de rendimento e cobertura foliar relativa, esta avaliada aos $20 \mathrm{DAE}$, indicou ajustes

Tabela 1 - Parâmetros estimados e ajustes obtidos para perdas de rendimento de grãos de soja em função da área e cobertura foliares relativas de picão-preto e guanxuma e de épocas de semeadura da soja, em Passo Fundo-RS, 1998/99 (ambiente 1), e em Eldorado do Sul - RS, 1999/00 (ambiente 2)

\begin{tabular}{|c|c|c|c|c|c|c|c|c|c|}
\hline \multirow{3}{*}{ Situação investigada } & \multicolumn{3}{|c|}{ Parâmetro } & \multirow{2}{*}{\multicolumn{2}{|c|}{$\begin{array}{l}\text { Soma dos quadrados } \\
\text { dos resíduos }\end{array}$}} & \multirow{2}{*}{\multicolumn{2}{|c|}{$\begin{array}{c}\begin{array}{c}\text { Coeficiente de } \\
\text { determinação }\end{array} \\
\left(\mathrm{R}^{2}\right)\end{array}$}} & \multirow{2}{*}{\multicolumn{2}{|c|}{ Estatística F }} \\
\hline & \multirow{2}{*}{$\frac{\mathrm{A}^{\frac{1 /}{3}}}{\mathrm{q}^{\mathrm{3}^{-/}}}$} & \multicolumn{2}{|c|}{$\mathrm{B}^{2 /}$} & & & & & & \\
\hline & & $\mathrm{q}^{3 /}+$ & $\mathrm{m}^{4 /}$ & $\mathrm{A}^{\mathrm{1}^{\prime /}}$ & $\mathrm{B}^{2 /}$ & $\mathrm{A}^{\mathrm{1}^{/ /}}$ & $\mathrm{B}^{2 /}$ & $\mathrm{A}^{\mathrm{1}^{\prime}}$ & $\mathrm{B}^{2 / /}$ \\
\hline \multicolumn{10}{|l|}{$\begin{array}{l}\text { Ambiente 1: } \\
\text { Área foliar - picão }\end{array}$} \\
\hline $3 \mathrm{DAD}^{5 /}$ & 2,49 & 4,75 & 48,9 & $1.176,6$ & 854,8 & 0,60 & 0,71 & $87,3^{*} \underline{7}$ & $59,6^{*}$ \\
\hline 7 DAD & 1,19 & 5,02 & 35,3 & $3.774,3$ & $2.582,9$ & 0,07 & 0,37 & $28,0^{*}$ & $23,0^{*}$ \\
\hline $11 \mathrm{DAD}$ & 5,88 & 24,07 & 39,6 & $5.654,3$ & $3.780,9$ & 0,05 & 0,36 & $32,9^{*}$ & $27,3^{*}$ \\
\hline Análise conjunta & 2,41 & 11,65 & 34,7 & $14.128,9$ & $8.829,4$ & 0,01 & 0,35 & $73,8^{*}$ & $73,6^{*}$ \\
\hline \multicolumn{10}{|l|}{ Área foliar - guanxuma } \\
\hline $3 \mathrm{DAD}$ & 5,20 & 28,59 & 17,9 & $1.074,9$ & 810,7 & 0,28 & 0,45 & $22,6^{*}$ & $16,3^{*}$ \\
\hline $7 \mathrm{DAD}$ & 3,41 & 23,75 & 14,9 & $1.496,6$ & 995,4 & 0,01 & 0,14 & $8,8^{*}$ & $9,7^{*}$ \\
\hline $11 \mathrm{DAD}$ & 13,90 & 70,51 & 18,6 & $1.791,8$ & $1.520,4$ & 0,24 & 0,16 & $19,9^{*}$ & $12,2^{*}$ \\
\hline Análise conjunta & 5,54 & 42,38 & 16,0 & $5.303,7$ & $3.536,8$ & 0,01 & 0,23 & $34,9^{*}$ & $37,1^{*}$ \\
\hline \multicolumn{10}{|l|}{ Cobertura foliar ${ }^{6 /}-$ picão } \\
\hline $3 \mathrm{DAD}$ & 0,90 & 1,41 & 49,8 & $1.522,8$ & $1.361,8$ & 0,48 & 0,53 & $63,6^{*}$ & $34,4^{*}$ \\
\hline $7 \mathrm{DAD}$ & 0,56 & 1,04 & 47,1 & $2.630,5$ & $2.323,9$ & 0,36 & 0,43 & $47,6^{*}$ & $26,4^{*}$ \\
\hline $11 \mathrm{DAD}$ & 1,16 & 2,69 & 44,8 & $4.967,9$ & $4.260,7$ & 0,16 & 0,28 & $39,8^{*}$ & $23,1^{*}$ \\
\hline Análise conjunta & 0,82 & 1,75 & 43,6 & $10.204,2$ & $8.606,6$ & 0,25 & 0,37 & $122,6^{*}$ & $23,4^{*}$ \\
\hline \multicolumn{10}{|l|}{ Cobertura foliar ${ }^{6 /}-$ guanxuma } \\
\hline $3 \mathrm{DAD}$ & 0,76 & 1,76 & 21,8 & $1.050,4$ & 896,8 & 0,29 & 0,40 & $23,5^{*}$ & $14,0^{*}$ \\
\hline $7 \mathrm{DAD}$ & 0,71 & 1,07 & 39,2 & 791,7 & 751,9 & 0,32 & 0,36 & $30,0^{*}$ & $15,1^{*}$ \\
\hline $11 \mathrm{DAD}$ & 4,36 & 23,03 & 19,4 & $1.970,1$ & $1.367,9$ & 0,01 & 0,24 & $16,7^{*}$ & $15,3^{*}$ \\
\hline Análise conjunta & 0,85 & 13,09 & 13,8 & $5.166,0$ & $3.936,4$ & 0,01 & 0,14 & $37,0^{*}$ & $31,0^{*}$ \\
\hline \multicolumn{10}{|l|}{$\begin{array}{c}\text { Ambiente } 2: \\
\text { Cobertura foliar }{ }^{6}-\text { picão }\end{array}$} \\
\hline $3 \mathrm{DAD}$ & 0,73 & 5,57 & 28,6 & $1.129,7$ & 409,0 & 0,24 & 0,72 & $32,2^{*}$ & $48,0^{*}$ \\
\hline $7 \mathrm{DAD}$ & 0,89 & 1,65 & 54,2 & $1.305,5$ & $1.233,5$ & 0,48 & 0,51 & $48,7^{*}$ & $23,5^{*}$ \\
\hline $11 \mathrm{DAD}$ & 6,69 & 36,56 & 48,3 & $2.425,4$ & $1.778,6$ & 0,42 & 0,57 & $51,4^{*}$ & $33,2^{*}$ \\
\hline Análise conjunta & 1,25 & 26,72 & 32,0 & $11.610,2$ & $5.719,4$ & 0,01 & 0,38 & $43,3^{*}$ & $58,5^{*}$ \\
\hline Cobertura foliar ${ }^{6 /}-$ guanxuma & & & & & & & & & \\
\hline $20 \mathrm{DAD}$ & 1,22 & 1,62 & 45,0 & $1.997,7$ & $1.935,6$ & 0,58 & 0,59 & $38,3^{*}$ & $17,9^{*}$ \\
\hline $24 \mathrm{DAD}$ & 0,96 & 0,86 & 13,8 & $1.342,8$ & $13.410,0$ & 0,47 & 0,47 & $47,7^{*}$ & $21,5^{*}$ \\
\hline $28 \mathrm{DAD}$ & 1,48 & 5,27 & 42,6 & $1.672,1$ & 589,6 & 0,46 & 0,81 & $32,9^{*}$ & $50,3^{*}$ \\
\hline Análise conjunta & 1,13 & 2,29 & 51,0 & $5.225,2$ & $4.562,6$ & 0,50 & 0,56 & $118,8^{*}$ & $68,0^{*}$ \\
\hline
\end{tabular}

1/ Calculado pela equação $\mathrm{P}_{\mathrm{r}}=(100 * \mathrm{q} * \mathrm{X}) /(1+((\mathrm{q}-1) * \mathrm{X}))$, em que: $\mathrm{P}_{\mathrm{r}}=$ perda de rendimento; $\mathrm{X}=$ área foliar ou cobertura foliar relativas. ${ }^{2 /}$ Calculado pela equação $\mathrm{P}_{\mathrm{r}}=(100 * \mathrm{q} * \mathrm{X}) /(1+((\mathrm{q} / \mathrm{m})-1) * \mathrm{X})$, em que: $\mathrm{P}_{\mathrm{r}}=$ perda de rendimento; $\mathrm{X}=$ área foliar ou cobertura foliar relativas. ${ }^{3 /}$ Coeficiente de dano relativo, estimado pelo modelo de regressão. ${ }^{4 /}$ Perda máxima de rendimento da cultura, estimada pelo modelo de regressão. ㅌ/ Época de semeadura da soja em dias após a dessecação da cobertura vegetal. [// Avaliada visualmente. 근 Indica significância a 5\% de probabilidade. 
com tendências semelhantes às observadas quando do uso da variável área foliar relativa (Tabela 1). Novamente, a inclusão dos parâmetros "q" e "m" num mesmo modelo aumentou os valores de $\mathrm{R}^{2}$ e diminuiu os de SQR, o que indica melhor ajuste dos dados.

Ao observar conjuntamente os resultados contidos na Tabela 1 , pode-se constatar que os efeitos provocados pela interferência de picão-preto e guanxuma em soja podem ser preconizados pela cobertura foliar relativa, a qual integra os efeitos da partição relativa da área foliar das plantas daninhas e sua arquitetura de dossel (Berti \& Sattin, 1996). Além disso, o modelo que utiliza a cobertura foliar relativa estima adequadamente o efeito de densidades de plantas daninhas, fluxos diferentes de plantas daninhas, bem como integra o período entre a emergência da cultura e a das plantas daninhas, constituindo-se, assim, em medida precisa que pode substituir a área foliar relativa no início da estação de crescimento (Kropff \& Lotz, 1992). Diversos autores usaram com sucesso a cobertura foliar relativa em vez da área foliar relativa como variável explicativa no modelo de Kropff \& Spitters (Lotz et al., 1994; Berti \& Sattin, 1996; Vitta \& Fernandez Quintanilla, 1996). Também foi constatado que, usando a cobertura relativa como variável explicativa, a variabilidade entre ambientes tende a se reduzir (Berti \& Sattin, 1996); no entanto, conforme se observa na Tabela 2, no caso desses experimentos, isso se verificou apenas para guanxuma.

Outra abordagem para uso da cobertura foliar relativa e dos parâmetros "q" e " $m$ " na predição das perdas de rendimento de culturas dá-se a partir da integração de dados obtidos em condições controladas com aqueles originados em campo. A partir da análise de regressão com dados de massa seca (MS) da cultura como variável dependente e densidade da soja como variável independente, obtiveram-se em bioensaios os seguintes resultados: para soja em monocultivo, $1 / \mathrm{MS}=0,0322+0,0254 \mathrm{X}$ e $\mathrm{R}^{2}=0,99$; para picão-preto:soja, $1 / \mathrm{MS}=0,0705$ $+0,039 X$ e $R^{2}=0,91$; e, para guanxuma: soja, $1 / \mathrm{MS}=0,0464+0,038 \mathrm{X} \mathrm{e} \mathrm{r}^{2}=0,96$. As estimativas dos parâmetros "q" e "m" foram, respectivamente, de 20,3 e 39,4 para picão-preto e 7,4 e 39,4 para guanxuma. Os modelos gerados após integração dos valores de "q" e "m" na equação 3 foram: para picão-preto, $\mathrm{P}_{\mathrm{r}}=$ $(100 * 20,3 * X) /(1+((20,3 / 0,39)-1 * X) ;$ e, para guanxuma, $\mathrm{P}_{\mathrm{r}}=(100 * 7,4 * \mathrm{X}) /(1+((7,4 / 0,39)-$ $1 * \mathrm{X})$.

No caso do picão-preto, os valores de perda de rendimento observados em campo e estimados em função da cobertura foliar relativa obtida por Rizzardi (2002), com o método fotográfico, associaram-se satisfatoriamente $(\mathrm{r}=$ 0,$81 ; \mathrm{p}<0,05$ ) com os valores ajustados pelo modelo a partir dos dados obtidos nos bioensaios (Figura 1). Chama a atenção o fato de as curvas com dados estimados em campo e em bioensaios apresentarem as mesmas tendências, o que é confirmado pelo coeficiente de correlação $(r=0,96 ; p<0,05)$.

Tabela 2 - Estatística F das análises comparativas entre épocas de semeadura da soja em experimentos com picão-preto e guanxuma realizados em Passo Fundo-RS, 1998/99 (ambiente 1), e em Eldorado do Sul-RS, 1999/00 (ambiente 2)

\begin{tabular}{|l|c|c|}
\hline \multirow{2}{*}{ Situação investigada } & \multicolumn{2}{c|}{ Modelo testado } \\
\cline { 2 - 3 } & \multicolumn{1}{|c|}{$\mathrm{A}^{\mathbf{1}^{\prime}}$} & \multicolumn{1}{c|}{$\mathrm{B}^{\frac{2}{}}$} \\
\hline Ambiente 1: & & \\
Área foliar - picão & $7,5^{*}$ & $2,3^{\mathrm{ns}}$ \\
Área foliar - guanxuma & $4,8^{*}$ & $0,7^{\mathrm{ns}}$ \\
Cobertura foliar - picão & $2,7^{\mathrm{ns}}$ & $0,9^{\mathrm{ns}}$ \\
Cobertura foliar - guanxuma & $8,0^{*}$ & $3,2^{*}$ \\
\hline Ambiente 2: & & \\
Cobertura foliar - picão & $20,8^{*}$ & $4,5^{*}$ \\
Cobertura foliar - guanxuma & $0,6^{\mathrm{ns}}$ & $1,2^{\mathrm{ns}}$ \\
\hline
\end{tabular}

1/ Calculado pela equação $\mathrm{P}_{\mathrm{r}}=(100 * \mathrm{q} * \mathrm{X}) /(1+((\mathrm{q}-1) * \mathrm{X}))$, em que: $P_{r}=$ perda de rendimento; $X$ = área foliar ou cobertura foliar relativas; $\mathrm{q}=$ parâmetro estimado pelo modelo. $\stackrel{2}{=}$ Calculado pela equação $P_{r}=\left(100 * q^{*} X\right) /(1+((q / m)-1) * X)$, em que: $P_{r}=$ perda de rendimento; $\mathrm{X}=$ área foliar ou cobertura foliar relativas; $\mathrm{q} e$ $\mathrm{m}=$ parâmetros estimados pelo modelo.

* Valor de F significativo a 5\% de probabilidade. ${ }^{\text {ns }}$ Valor de F não-significativo a $5 \%$ de probabilidade.

Para guanxuma, utilizaram-se os valores de cobertura foliar relativa obtidos pelo método fotográfico com digitalização das fotos por Rizzardi (2002). Também para essa planta daninha houve associação satisfatória dos valores de cobertura observados em campo com 


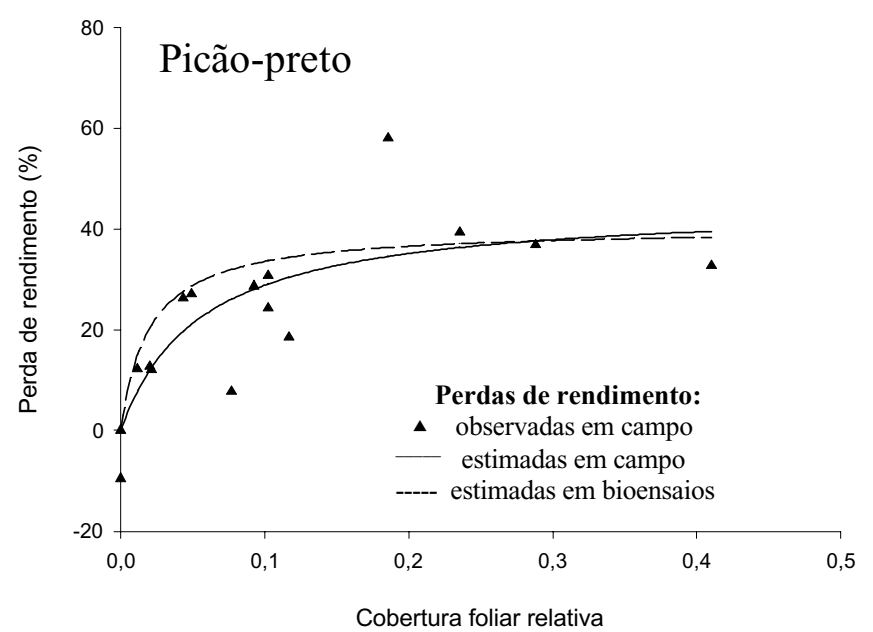

Coeficientes de correlação linear entre perdas de rendimento:

- observadas em campo e estimadas em bioensaios: $r=0,81(\mathrm{p}<0,05)$;

- estimadas em campo e estimadas em bioensaios: $\mathrm{r}=0,96(\mathrm{p}<0,05)$.

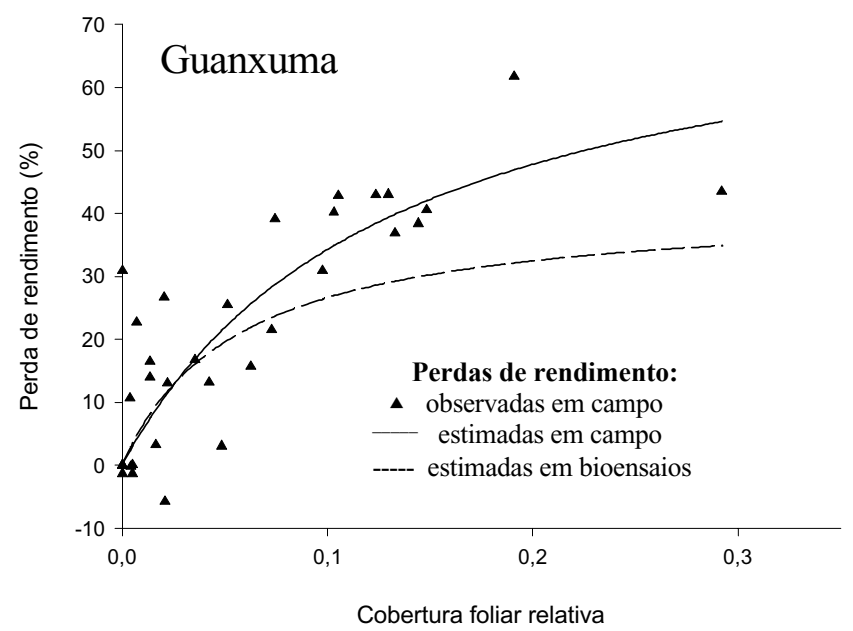

Coeficientes de correlação linear entre perdas de rendimento:

- observadas em campo e estimadas em bioensaios: $r=0,81(\mathrm{p}<0,05)$;

- estimadas em campo e estimadas em bioensaios: $r=0,99(\mathrm{p}<0,05)$.

Figura 1 - Associação entre perdas de rendimento de grãos de soja observadas e estimadas por meio de modelo de regressão, em função das coberturas foliares de picão-preto e guanxuma em relação à de soja. Eldorado do Sul-RS, 1999/00 (campo), e Porto Alegre-RS, 2000/01 (bioensaios).

os ajustados pelo modelo e obtidos nos bioensaios $(r=0,81 ; p<0,05)$. Percebe-se que, até o nível aproximado de $15 \%$ de perda no rendimento da soja, as curvas ajustadas com dados provenientes de campo e dos bioensaios foram equivalentes (Figura 1), o que é confirmado pela alta associação entre os valores estimados em campo e nos bioensaios ( $r=0,99 ; \mathrm{p}<0,05)$.

Diante desses resultados, demonstra-se que os parâmetros "q" e "m", estimados em condições controladas, representam uma alternativa que melhora a capacidade preditiva dos modelos que estimam as perdas de rendimento causadas por plantas daninhas, uma vez que, além do ajuste satisfatório propiciado, bioensaios são fáceis e rápidos de serem conduzidos, podendo incluir uma amplitude de condições de ambiente e ampla gama de espécies daninhas.

\section{LITERATURA CITADA}

BERTI, A.; SATTIN, M. Effect of weed position on yield loss in soybean and a comparison between relative weed cover and other regression models. Weed Res., v. 36, n. 3, p. 249-258, 1996.

CHIKOYE, D.; SWANTON, C. J. Evaluation of three empirical models depicting Ambrosia artemisiifolia competition in white bean. Weed Res., v. 35, n. 5, p. 421428, 1995. 
COUSENS, R. An empirical model relating crop yield to weed and crop density and a statistical comparison with other models. J. Agric. Sci., v. 105, n. 3, p. 513-521, 1985 .

COUSENS, R. et al. The use of biologically realistic equations to describe the effects of weed density and relative time of emergence on crop yield. Weed Sci., v. 35, n. 5, p. $720-725,1987$.

\section{EMPRESA BRASILEIRA DE PESQUISA}

AGROPECUÁRIA - EMBRAPA. Centro Nacional de Pesquisa de Solos. Sistema brasileiro de classificação de solos. Brasília: 1999. 412 p.

FLOREZ, J. A. et al. Predicting rice yield losses caused by multispecies weed competition. Agron. J., v. 91, n. 1, p. 87-92, 1999.

GOMEZ, K. A.; GOMEZ, A. A. Statistical procedures for agricultural research. 2.ed. New York: Wiley, 1984. $680 \mathrm{p}$.

HASHEM, A.; RADOSEVICH, R. S.; ROUSH, M. L. Effect of proximity factors on competition between winter wheat (Triticum aestivum) and italian ryegrass (Lolium multiflorum). Weed Sci., v. 46, n. 2, p. 181-190, 1998.

KNEZEVIC, S. Z.; WEISE, S. F.; SWANTON, C. J. Comparison of empirical models depicting density of Amaranthus retroflexus L. and relative leaf area as predictors of yield loss in maize (Zea mays L.). Weed Res., v. 35, n. 4., p. 207-214, 1995.

KROPFF, M. J.; LOTZ, L. A. P. Optimization of weed management systems: the role of ecological models of interplant competition. Weed Technol., v. 6, n. 2, p. 462470, 1992.

KROPFF, M. J.; SPITTERS, J. T. A simple model of crop loss by weed competition from early observations on relative leaf area of the weeds. Weed Res., v. 31, n. 2, p. 97-105, 1991.

KROPFF, M. J.; WEAVER, S. E.; SMITS, M. A. Use of ecophysiological models for crop-weed interference: relations amongst weed density, relative time of weed emergence, relative leaf area, and yield loss. Weed Sci., v. 40, n. 2, p. 296-301, 1992.

LOTZ, L. A. P. et al. Prediction of the competitive effects of weeds on crop yields based on the relative leaf area of weeds. Weed Res., v. 36, n. 1, p. 93-101, 1996.
LOTZ, L. A. P. et al. Techniques to estimate relative leaf area and cover of weeds in crops for yield loss prediction. Weed Res., v. 34, n. 3, p. 167-175, 1994.

NORRIS, R. F. Case history for weed competition/ population ecology:barnyardgrass (Echinochloa crusgalli) in sugarbeets (Beta vulgaris). Weed Technol., v. 6, n. 1, p. 220-227, 1992.

OLIVER, L. R. Principles of weed threshold research. Weed Technol., v. 2, n. 4, p. 398-403, 1988.

RIZZARDI, M. A. Nível de dano econômico para tomada de decisão no controle de picão-preto (Bidens spp.) e guanxuma (Sida rhombifolia $\mathrm{L}$.) na cultura da soja. 2002. 175 f. Tese (Doutorado em Fitotecnia - Plantas de Lavoura) - Universidade Federal do Rio Grande do Sul, Porto Alegre, 2002.

ROUSH, M. L. et al. A comparison of methods for measuring effects of density and proportion in plant competition experiments. Weed Sci., v. 37, n. 2, p. 268$275,1989$.

SARTORATO, I.; BERTI, A.; ZANIN, G. Estimation of economic thresholds for weed control in soybean (Glycine $\max ($ L.) Merr.). Crop Protec., v. 15, n. 1, p. 63-68, 1996.

SAS - INSTITUTE. User's guide: version 6. 4.ed. Cary: 1989. $846 \mathrm{p}$

STORKEY, J. et al. The importance of mortality in weed populations between autumn and spring on the reliability of yield loss predictions in winter wheat. In: BRIGHTON CROP PROTECTION CONFERENCE, 1997, Brighton. Proceedings... Brighton: British Crop Protection Council, 1997. p. 1025-1030.

VAN ACKER, R. A.; LUTMAN, P. J. W.; FROUDWILLIAMS, R. J. Predicting yield loss due to interference from two weed species using early observations of relative weed leaf area. Weed Res., v. 37, n. 5, p. 287-299, 1997.

VITTA, J. I.; FERNANDEZ QUINTANILLA, C. Canopy measurements as predictors of weed-crop competition.

Weed Sci., v. 44, n. 3, p. 511-516, 1996.

WEAVER, S. E. Size-dependent economic thresholds for three broadleaf weed species in soybeans. Weed Technol., v. 5 , n. 3, p. 674-679, 1991. 